\title{
Memory and Trauma Transmission in Haruki Murakami's After the Quake: Postmemory Study
}

\author{
Haris Kurniawati ${ }^{1}$, Lia Haryana ${ }^{2}$ and Titin Astina ${ }^{3}$ \\ ${ }^{1,3}$ Gadjah Mada University, Indonesia \\ ${ }^{2}$ Universitas Negeri Malang, Indonesia
}

\begin{abstract}
This study analyzes the creative process of a postmemory in Haruki Murakami's After the Quake concerning to memory transmission process from the first generation to the next generation. This study aims to criticize the structure of traumatic memory transmission in Haruki Murakami's After the Quake on the traumatic impressions which appear. The theory used to analyze this work is postmemory theory proposed by Marianne Hirsch. This study is descriptive qualitative study. The results of this study are: 1) there are two transmissions which constr uct Haruki Murakami's After the Quake, namely familial transmission and affilial transmission. In the process of transmission, gender plays a role to whom and what narrative is told to the post-generation; 2) the role of gender in Haruki Murakami's After the Quake can be seen from infantilized committed toward Japanese citizens and Hyper-masculinized committed toward Aum Shinrikyo as an icon of destruction. Haruki Murakami organized cropping by highlighting Japanese narration to change the stereotype since Murakami considers that not all Japanese citizens are criminals who involved in international-scale terrorism, Aum Shinrikyu sect.
\end{abstract}

Keywords: After the Quake, Postmemory, Transmission, Trauma

\section{Introduction}

Language is one of the main focuses because it helps restore relationships that might be lost between humans and the whole world. This study analyzes a postmemory work entitled Honey Pie and Super-Frog Saves Tokyo which is included in the collection of After the Quake by Haruki Murakami. The researcher chooses to analyze one of Murakami's best works because Haruki Murakami is a Japanese best-seller writer. According to Maiko (2008), his work in fiction and nonfiction has received many critics' claims and a number of awards, both in Japan and in abroad, including the World Fantasy Award (2006) and the Frank O'Connor International Short Story Award (2006). All his works were awarded prizes at Franz Kafka Prize (2006) and Jerusalem Prize (2009). Murakami has also translated a number of his works into English, such as A Wild Sheep Chase (1982), Norwegian Wood (1987), The Wind-Up Bird Chronicle (1994-1995), Kafka on the Shore (2002), and 1Q84 (2009-2010).

Other phenomenal fiction are the collection of After the Quake stories which took traumatic stories related to the Holocaust in Japan, namely Kobe earthquake in January 1995 and Aum Shinrikyo bombing terror two months after earthquake. There are 6 short stories entitled UFO in Kushiro, Landscape with Flatiron, All God's Children Can Dance, Thailand, Super-Frog Saves Tokyo, and Honey Pie. However, researchers only focus on analyzing two of the six short stories namely SuperFrog Saves Tokyo and Honey Pie.

Collective trauma is an important theme in Murakami's writing. In this collective trauma, there is a process of transmission. Memory transmission usually occurs in family life from parents to children, 
grandparents to grandchildren and others. However, it is possible that strong memory transmission also occurs from outside the family environment. Postmemory is a type of traumatic memory that is not directly experienced by a person. It is different from ordinary memories because of the very profound influence. Not only applied to holocaust survival, but also to disaster victims. In postmemory, there is transmission process. Through this transmission process, the postmemory generation gets a memory from the previous generation. Past memories have a tremendous and unexpected impact on present and future life.

According to Kumalasari (2016), postmemory works are works that contain emanation which means the desire and projection for the next generation to find what have been lost, complete what have been scattered, or fix the traumatic past of intra-generation. In postmemory works, past memories is the basic foundation of stories by combining the memories and imaginations of others. Postgeneration builds a new place in his mind to save the past memories.

Based on this background of study, the questions of research problems are how the main character transmits memory and trauma from traumatic experiences? And how do traumatic events shape attitudes and behavior? This memory depiction can be transmitted to the present generation in the short stories entitled Honey Pie and Super-Frog Saves Tokyo by Haruki Murakami. To answer the research question, Marianne Hircsh's postmemory theory is considered suitable to analyze this literary works.

This study focuses on memory transmission related to traumatic experiences presented in the form of short stories. This study uses descriptive qualitative analysis. The author chooses this work to elaborate on how memory is transmitted to the next generation and how traumatic events shape attitudes and behavior. The researcher uses the postmemory theory to look at memory transmission and traumatic experiences or how the traumatic impression is represented in the literary work. The data from the analytical unit (sentences) will be analyzed by using postmemory theory which are related to the questions of trauma and memory transmission.

\section{Discussion}

Postmemory explains the post-generation relationships which involve personal, collective, or cultural trauma from those who lived in the past (previous generations). The experience is not directly experienced but by remembering through stories, photos, images, and the behavior of people around post-generation when he grows up. However, this experience is deeply and effectively transmitted toward post-generation. Therefore, it makes the transmitted memory seems like their own memory. Postmemory is connected to the past not only by recall but also by investing in imagination, projections, and creations. The transmitted memory is usually a traumatic experience because traumatic impressions are more dominant and more strongly recorded for individuals. Then, this traumatic impression is transmitted to the next generation. In postmemory, the position of identity is not so emphasized, but rather the generational structure of the embedded transmission is very significant in the form of mediation. In Honey Pie, traumatic memory begins to be explored from the characters Junpei, Sayoko, and Takatsuki through the character of Sala. Therefore, the traumatic transmission in Honey Pie can be seen through two ways, namely familial transmission and affiliative transmission.

\subsection{Familial Transmission}

The memory of Sayoko and Takatsuki was still alive in Junpei's mind which continued to haunt him because Junpei felt unfinished with him at that time. Sayoko and Takatsuki are Junpei's past. The memory of the triangular love journey is strongly reflected in Junpei's memory. The memory was recalled when Sala, the daughter of Sayoko and Takatsuki, wanted Junpei to recite a fairy tale before

going to bed. Thus, the memory which had been buried for years spontaneously returned and reminded him of the traumatic event. Sala asked him to tell, "Junpei often made up stories for Sala when she 
went to bed. And whenever she didn't understand something, she would ask him to explain. Junpei gave a lot of thought to his answers."

In Honey Pie, there is a memory transmission between Junpei as the first generation and Sala as the second generation. Sala can be said as a historical agent. In postmemory, historical agents are positioned as carriers of personal and collective trauma that existed in previous generations although Sala does not really know the events in the past. It shows that the memory of Sayoko and Takatsuki adopted by Sala was not directly transmitted by his mother, Sayoko, but through a close friend of his mother as the first generation agent who was still alive. Familial transmission can be found in Honey Pie through the following quote:

He thought about his early days in college. He could still hear Takatsuki the first time they met in class saying, "Hey, let's get something to eat," in that warm way of his, and he could see Takatsuki's friendly smile that seemed to say, Hey, relax. The world is just going to keep getting better and better. Where did we eat that time? Junpei wondered, and what did we have? He couldn't remember, though he was sure it was nothing special (Murakami, 2012).

Tonkichi had the same thought as Sala: he would use the honey that Masakichi had collected to bake honey pies. It didn't take him long to realize that he had a real talent for making crisp, delicious honey pies. Masakichi took the honey pies to town and sold them to the people there. The people loved Tonkichi's pies and bought them by the dozen. So Tonkichi and Masakichi never had to separate again: they lived happily ever after in the mountains, best friends forever (Murakami, 2012).

Junpei told a story to Sala about a bear named Masakichi and Tonkichi as a metaphor for his traumatic experiences and past memories with Takatsuki and Sayoko. The memory of the first generation has a strong influence. Therefore, it makes historical agents on the basic foundation gives an overshadow effect. If the overshadow continues, it will make Sala seem to enter the world. It is in line with the statement "You and he had exactly the same ideas and Tonkichi had the same thought as Sala." This unconsciously created an investment of imagination and projections of Junpei's past love story which had carved out trauma.

\subsection{Affilial Transmission}

The story of Junpei's past was also transmitted to Sala in an affiliative manner. Sala experienced a traumatic experience. Junpei individual experience is closely related to collective experiences which cause trauma. The collective experiences are the relationship between the earthquake which had made him to lose his loved one and also his triangular love story with Takatsuki who had made him lose Sayoko.

In the process of transmission, Sala gained memory of the earthquake through news reports. The Kobe earthquake occurred on Tuesday, January $17^{\text {th }} 1995$ in the southern part of Hyogo prefecture in southern Japan. This earthquake is also known as the Great Hanshin-Awaji Earthquake in Japan around a quarter to nine nights with a strength of about 7.2 on the Richter scale. Sala is haunted by Earthquake Man every night. Sala's transmission and trauma process can be identified through the following narrative:

"The Earthquake Man. He came and woke me up. He told me to tell you. He said he has the box ready for everybody. He said he's waiting with the lid open. He said I should tell you that, and you'd understand" (Murakami, 2012).

"I think she saw too many news reports on the earthquake. It was too much for a fouryear-old. She wakes up at around the time of the quake. She says a man woke her up, 
somebody she doesn't know. The Earthquake Man. He tries to put her in a little box-way too little for anyone to fit into. She tells him she doesn't want to get inside, but he starts yanking on her arm-so hard her joints crack—and he tries to stuff her inside. That's when she screams and wakes up" (Murakami, 2012).

"But Junpei did not try to call his parents. The rift was too deep, and had gone on too long for there to be any hope of reconciliation. He flew back to Tokyo and resumed his normal life. He never turned on the television, and hardly looked at a newspaper." (Murakami, 2012).

Based on the narration above, news reports are something outside the scope of the family that has a considerable influence in shaping someone memory. It is because news reports have legitimacy as a trusted medium by the wider community to obtain the truth of an event. So it can be seen how much the power of memory transmission is affilial. Hence, the memory continues to imprint in Sala's mind which makes her trauma and hallucinates about Earthquake Man.

From the results of the researchers' analysis, Earthquake Man is Junpei. This can be seen from Sala's statement which states "The Earthquake Man. He came and woke me up ..." This indicates that Junpei's traumatic memory which is difficult to express his love for Sayoko was successfully transmitted to Sala. Sala implicitly revealed what Junpei meant to say to Sayoko for a long time.

\subsection{Hypermasculinized against Aum Shinrikyo}

The image of Aum Shinrikyo was presented as a perpetrator in the form of Aum Shinrikyo's treatment toward Japanese citizens. Aum Shinrikyo is renowned heretical school of Japan which combines the teachings of several religions and yoga. This heretical school was formed in 1984. In 1995, it succeeded in attracting international attention after attacking the subway station with Sarin gas. Aum Shinrikyo has the largest terrorism network in Canada, Kazakhstan, and the United States. There are several various terrorist activities, kidnappings, and killings initiated by this sect that have been recorded. Since the gas attack on the subway in 1995, they have been operating secretly by changing their name to Aleph or Hikari no Wa. Hypermasculinized against Aum Shinrikyo can be found in the short story Super-Frog Saves Tokyo through the following quote:

"I feel no personal animosity toward Worm. I don't see him as the embodiment of evil. Not that I would want to be his friend, either: I just think that, as far as the world is concerned, it is in a sense all right for a being like him to exist. The world is like a great big overcoat, and it needs pockets of various shapes and sizes. But right at the moment Worm has reached the point where he is too dangerous to ignore. With all the different kinds of hatred he has absorbed and stored inside himself over the years, his heart and body have swollen to gargantuan proportions-bigger than ever before" (Murakami, 2012).

History recorded that Aum Shinrikyu was a prepertator. Katagiri figure received a traumatic memory experienced by Tokyo citizens after the Japanese earthquake followed by terrorism, and subway assault in Tokyo by Aum Shinrikyu. Haruki Murakami described hypermaskulinized against Aum Shinrikyu. Hirsch (2012) says that cropping strategy is a frequently-used strategy by postgeneration writers in his work. Murakami cropped in his After the Quake book. Murakami did not necessarily show generalization and internalization of Aum Shinrikyu who had been considered a terrorist organization that betrayed Japan. Through the giant worm, Murakami described that Aum Shinrikyu was a scourge for the world but did not need to be feared. Giant worm is a metaphor of Aum Shinrikyu who wants to control the world and make damage to strengthen the hegemony of his power. 


\subsection{Feminized against Japanese citizens}

Murakami described that Japanese citizens were feminized or infantilized through hypermaskulinized against Aum Shinrikyu. Feminized against Japanese citizens can be seen in SuperFrog Saves Tokyo through the following quote:

"I'm an absolutely ordinary guy. Less than ordinary. I'm going bald, I'm getting a potbelly, I turned forty last month. My feet are flat. The doctor told me recently that I have diabetic tendencies. It's been three months or more since I last slept with a woman-and I had to pay for it. I do get some recognition within the division for my ability to collect on loans, but no real respect. I don't have a single person who likes me, either at work or in my private life. I don't know how to talk to people, and I'm bad with strangers, so I never make friends. I have no athletic ability, I'm tone-deaf, short, phimotic, nearsighted-and astigmatic. I live a horrible life. All I do is eat, sleep, and shit. I don't know why I'm even living. Why should a person like me have to be the one to save Tokyo?" (Murakami, 2012).

According to Hirsch (2012), usually the authors of post-memory works justify the victims of the holocaust as innocent people. The author's tendencies or alignments will be seen from the narrative. Although it does not justify the evil worm, the narratives about the goodness of the giant worm against Japan are not presented. Through the Katagiri figure, the Frog figure told him to save the world. Katagiri experienced a traumatic experience. There is a connection between experiences of individual memory and collective memory. By recalling this event, we can investigate how Murakami described trends, ideologies, and events rooted in individual memories that originate from collective memory. It is able to bind a country together and reveal something about the relationship between individual experience and collective experience. Thus, Murakami's views through the Katagiri figures represent Japanese citizens. Katagiri is narrated as an ordinary person who does not have superpowers.

\section{Conclusions}

Based on the results of the discussion above, it can be concluded that the traumatic memory of Haruki Murakami in Honey Pie is formed by familial transmission and affilial transmission. In familial transmission, Sala gets past memories of the love triangle Junpei, Sayoko, and Takatsuki from the Junpei fairy tale about bears named Masakichi and Tonkichi. In an affilial transmission, Sala gained a past memory of the Earthquake in Kobe from news reports.

In the short story Super-Frog Saves Tokyo, it is shown that Aum Shinrikyu experienced Hypermaskulinized. While Japanese citizens experience Feminized or Infantilized. As an author, Haruki Murakami did cropping by highlighting Japanese narratives in order to change the inherent stereotype as one of the prepetrators. Murakami considers that not all Japanese citizens are criminals involved in international-scale terrorism, the Aum Shinrikyu sect.

\section{Acknowledgments}

This paper is supported by Indonesia Endowment Fund for Education or LPDP. The author would also like to show her gratitude to the reviewers on the helpful comments and suggestions for the improvement of the presentation.

\section{References}

[1] Hirsch, Marianne. 2012. Family Frame: Photography, Narrative, and Postmemory. Cambridge, Massachussets: Harvard University Press. 
[2] Hirsch, Marianne. 2012. The Generation of Postmemory: Writing and Visual Culture After Holocaust. New York: Columbia University Press.

[3] Kumalasari, Isti. 2016. The Book Thief Karya Markus Zuzak: Sebuah Kajian Postmemory. Tesis. Yogyakarta: Faculty of Cultural Science. Gadjah Mada University.

[4] Murakami, Haruki. 2003. After the Quake. Random House Inc.

[5] Maiko, Hisada (November 1995). "Murakami Haruki". Kyoto Sangyo University. Archived from the real version at May 23 $3^{\text {th }}$,2008. Retrieved at April $24^{\text {th }}, 2019$. 